\title{
Artificial Neural Network based Prediction of Solar Radiation for Indian Stations
}

\author{
Amit Kumar Yadav \\ Centre for Energy and Environment \\ National Institute of Technology \\ Hamirpur H.P. India-177005
}

\author{
S.S. Chandel \\ Centre for Energy and Environment \\ National Institute of Technology \\ Hamirpur H.P. India-177005
}

\begin{abstract}
The Artificial Neural Network (ANN) fitting tool is used for the prediction of solar radiation. Solar radiation data from 12 Indian stations with different climatic conditions are used for training and testing the ANN. The Levenberg-Marquard (LM) algorithm is used in this analysis. The results of ANN model are compared with measured data on the basis of root mean square error (RMSE) and mean bias error (MBE). It is found that RMSE in the ANN model varies $0.0486-3.562$ for Indian region.
\end{abstract}

\section{Keywords}

Solar radiation, Levenberg-Marquard (LM) algorithm , Artificial neural network.

\section{INTRODUCTION}

Solar radiation data are required for a number of solar thermal and Solar photovoltaic applications like solar power generation, solar heating, cooking, drying and solar passive design of buildings [1-4]. The measured solar radiation data are not available for most of the sites due to high cost, maintenance of the measuring instruments. As such, various empirical models have been used to predict monthly mean daily solar radiation all over the world [5-9].

The Artificial neural networks (ANNs) are used to solve a number of scientific problems. It has the capability to approximate any continuous non-linear function to arbitrary accuracy [10]. A multi-layer feed-forward neural network can approximate a continuous function due to its robustness, parallel architecture and fault tolerance capability. In past years, ANN models are used by a number of researchers to estimate solar radiation [11-15] and concluded that ANN model are proven to be superior to other empirical regression models.

Reddy [11] used Radial Basis Functions (RBF) and Multilayer Perceptron (MLP) models to predict solar radiation using data from eight stations in Oman. So"zen [12] determined the solarenergy potential in Turkey using artificial neural networks. A Rehman and Mohandes [15] estimated daily global solar radiation for Abha city in Saudi Arabia by taking air temperature, number of day and relative humidity as inputs to neural networks. The results obtained indicate that the mean absolute percentage error (MAPE) is $4.49 \%$. M.A. Behrang et. al [17] predicted daily global solar radiation for Dezful city in Iran by using different ANN techniques based on different combination of meteorological variables (day of the year, daily mean air temperature, relative humidity, sunshine hours, evaporation and wind speed). The MAPE for the Multilayer Perceptron (MLP) network is $5.21 \%$ while this value is $5.56 \%$ for Radial Basis Function (RBF) network. Mohandes et al. [16] has used RBF network for modeling solar radiation and compares its performance with MLP model by using latitude, longitude, altitude and sunshine duration as input parameters.
The average MAPE for the MLP network is 12.6 and the average MAPE for RBF networks is 10.1 .

In the present study, an ANN model is developed which can be used to predict solar radiation at any given location in India.

\section{ANNS FOR SOLAR RADIATION PREDICTION}

According to Haykin [18], a neural network is a massively parallel-distributed processor that has the capability for storing experiential knowledge and making it available for use. It works like human brain in two respects:the network through a learning process acquire the knowledge, and inter-neuron connection strengths known as synaptic weights are used to store the knowledge. ANN has the ability to handle large and complex systems with many inter-related parameters.It ignores insignificant excess data and concentrates on the more important inputs (Kalogirou [19]). The most popular and powerful learning algorithms in neural network, are the back propagation. This algorithm is based on the error-correction learning rule. The error back-propagation process consists of a forward pass and a backward pass. In the forward pass, input vectors are applied to the input layer of the network and its effect propagates through the network via connection weights and layer by layer. Finally, a set of outputs is produced as the actual response of network. During the forward pass, the synaptic weights of the network are fixed whereas during the backward pass, the synaptic weights of the network are all adjusted in accordance with the errorcorrection rule. The actual response of the network is subtracted from the desired (target) response to produce an error signal. This error signal is then propagated backward through the network (Haykin [18]).

This network consists of an input layer, an output layer and usually one or more hidden layers. The architecture used in this work, has an input layer of four inputs, one hidden layer with a tan-sigmoid activation function, f, defined by the logistic

function as $\phi=\frac{1}{1+e^{-n}}$ where $\mathrm{n}$ is the corresponding input [Fig.1]. For the output layer, a linear activation function 'Purelin' is used. The MATLAB Neural Network Fitting Toolbox (nftool), is used for the implementation. The algorithm 'TRAINLM' is used for the training of network.

\section{METEOROLOGICAL DATA AND} METHODOLOGY

In the present analysis 12 Indian locations, Ahmedabad, Mangalore, Mumbai, Kolkata, Chandigarh, Dehradun, Jodhpur, Lucknow, Nagpur, New Delhi, Shillong, Vishakapatnam are selected [Table 1]. The measured meteorological data by India Meteorological Department (IMD), and compiled by A.Mani [20] viz. monthly mean solar radiation on horizontal surface; mean duration sunshine per hour, height above sea level for these stations, are used. 


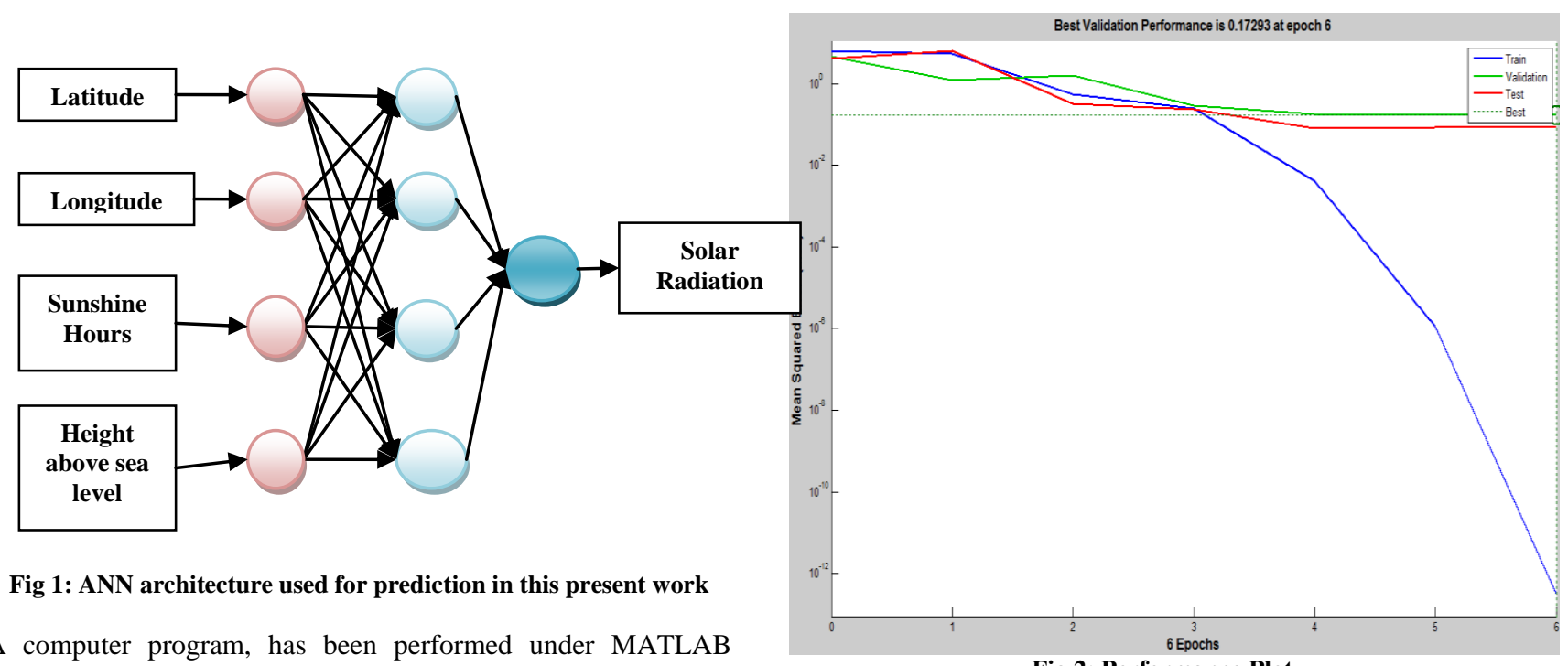

A computer program, has been performed under MATLAB 7.12.0.635 (R2011b) using Neural Network Fitting Tool (nftool).The geographical and sunshine hour data for cities Ahmedabad, Mangalore, Mumbai, Kolkata, Chandigarh, Dehradun, Jodhpur, Lucknow, are used for training data and the geographical and sunshine hour data for cities Nagpur, New Delhi, Shillong, Vishakapatnam, are used for testing.

Table.1. Geographical features of Stations in India

\begin{tabular}{|l|l|l|l|}
\hline Stations & $\begin{array}{l}\text { Latitude } \\
\left({ }^{\mathbf{O}} \mathbf{N}\right)\end{array}$ & $\begin{array}{l}\text { Longitude } \\
\left({ }^{\mathbf{}} \mathbf{E}\right)\end{array}$ & $\begin{array}{l}\text { Height } \\
\text { above sea } \\
\text { level (m) }\end{array}$ \\
\hline Ahmedabad & 23.07 & 72.63 & 169 \\
\hline Mangalore & 12.95 & 77.63 & 897 \\
\hline Mumbai & 19.12 & 72.85 & 14 \\
\hline Kolkata & 22.65 & 88.45 & 6 \\
\hline Chandigarh & 30.73 & 76.88 & 347 \\
\hline Dehradun & 30.31 & 78.03 & 683 \\
\hline Jodhpur & 26.3 & 73.02 & 224 \\
\hline Lucknow & 26.75 & 80.88 & 128 \\
\hline Nagpur & 21.15 & 79.12 & 311 \\
\hline New Delhi & 28.58 & 77.2 & 216 \\
\hline Shillong & 25.57 & 91.88 & 1598 \\
\hline Vishakapatnam & 17.72 & 83.23 & 3 \\
\hline
\end{tabular}

The statistical tests like mean absolute percentage error (MAPE), sum of square error (SSE), mean square error (MSE), absolute fraction of variance $\left(\mathrm{V}^{2}\right)$ are

$$
\begin{gathered}
\left(\frac{1}{n_{i=1}} \sum_{1}^{n}\left|\frac{S R_{i(\text { ANN })}-S R_{i(\text { actual })}}{S R_{i \text { (actual })}}\right|\right) \times 100 \quad \sum_{i=1}^{n}\left(S R_{i(\text { ANN })}-S R_{i(\text { actual })}\right)^{2} \\
\left(\frac{1}{n} \sum_{i=1}^{n}\left(S R_{i(A N N)}-S R_{i(\text { actual })}\right)^{2}\left(1-\left(\frac{\sum_{i=1}^{n}\left|S R_{i(A N N)}-S R_{i(\text { actual })}\right|^{2}}{\sum_{i=1}^{n} S R_{i \text { (actual })}}\right)\right) \times 100\right.
\end{gathered}
$$

respectively where $\mathrm{n}$ is number of inputs patterns, $S R_{i(A N N)}$ is predicted solar radiation by ANN, $S R_{i(\text { actual })}$ is actual solar radiation

\section{RESULTS AND DISCUSSION}

The performance curve is shown in Fig. 2. In this figure mean squared error have become small by increasing the number of epoch. The test set error and the validation set error has similar characteristics and no significant over fitting has occurred by epoch 6 (where best validation performance has occurred). 


\begin{tabular}{|l|c|c|c|c|c|}
\hline Chandigarh & 0.015 & 0.118 & 0.887 & 0.1567 & 99 \\
\hline Dehradun & 0.0132 & 0.1149 & 0.8998 & 0.1584 & 99.75 \\
\hline Jodhpur & 0.066 & 0.2581 & 1.8822 & 0.7994 & 98.69 \\
\hline Lucknow & 0.0502 & 0.2240 & 1.5699 & 0.6018 & 99.17 \\
\hline
\end{tabular}

The Error Histogram plot for Training data is shown in Fig 3 . for additional verification of network performance. Most of the data falls on zero error line which provides an idea to check the outliers to determine if the data is bad, or if those data points are different than the rest of the data.

The regression( $R$ value ) between the outputs and targets is a measure of how well the variation in the outputs is explained by the targets. The slope (m) and intercept (b) values in Fig 4 are $0.95,0.32$ respectively which predict the fit is good. The R-value is $91.96 \%$ for the total response as shown in Fig 4. The gradient plot shown in Fig 6 indicates about optimization techniques procedures to achieve global solutions.

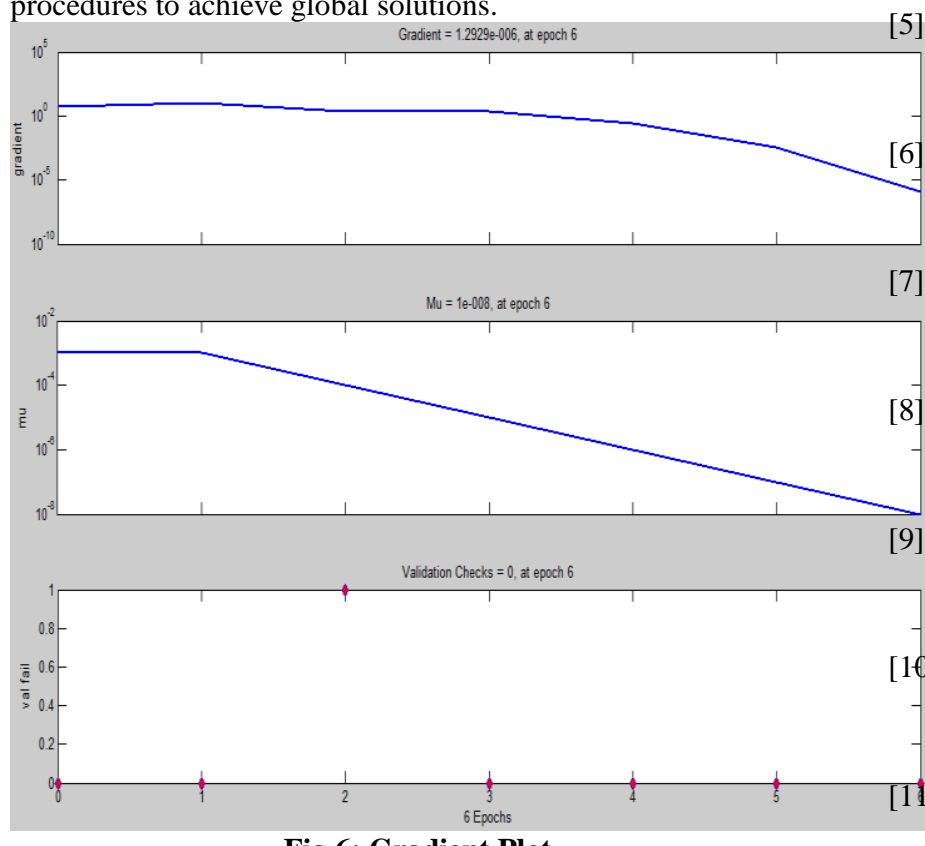

Fig 6: Gradient Plot

The predicted solar radiation values are close to the actual values for all months. A small deviation is observed for the calculated values. The maximum and minimum MAPE are $2.1462 \%$ and $0.2783 \%$ for Mangalore and Mumbai respectively. The best value of $\mathrm{V}^{2}$ is $99.95 \%$ for Mumbai. The minimum value of $\mathrm{V}^{2}$ is $98.69 \%$ for Jodhpur.

Table.3. Error values analysis of ANN during testing

\begin{tabular}{|l|l|}
\hline Stations & RMSE \\
\hline Nagpur & 3.562 \\
\hline New Delhi & 1.4610 \\
\hline Shillong & 2.5469 \\
\hline Vishakapatnam & 1.7123 \\
\hline
\end{tabular}

\section{CONCLUSION}

The use of ANN technique in modeling solar radiation, is reported. The study indicates that selected ANN model has lower RMSE.This model is developed by including latitude, longitude, sunshine hours and height above sea level of different states in India. A comparison of the model with the measured data revealed that the predictions of solar radiation using this model are in good agreement with the IMD measured data. As such the model developed, is suitable for predicting solar radiation for locations in India for which solar radiation is required for site specific solar energy applications especially for solar power generation.

\section{REFERENCES}

[1] Wong LT, Chow WK. Solar radiation model. Applied Energy 2001;69(3):191-224.

[2] Li DHW, Lam JC. Solar heat gain factors and the implications for building designs in subtropical regions. Energy and Buildings 2000;32(1):47-55.

[3] Lu Z, Piedrahita RH, Neto CDS. Generation of daily and hourly solar radiation values for modeling water quality in aquaculture ponds. Transactions of the ASAE 1998;41 (6):1853-9.

[4] KumarR,Umanand L. Estimation of global radiation using clearness index model for sizing photovoltaic system. Renewable Energy 2005;30(15):2221-33.

[5] Ertekin C, Yaldiz O. Comparison of some existing models for estimating global solar radiation for Antalya (Turkey) Energy Conversion and Management 2000;41(4):311-30.

6] Tadros MTY. Uses of sunshine duration to estimate the global solar radiation over eight meteorological stations in Egypt. Renewable Energy 2000;21(2):231-46.

[7] Almorox J, Hontoria C. Global solar radiation estimation using sunshine duration in Spain. Energy Conversion and Management 2004;45(9-10):1529-35.

[8] Menges HO, Ertekin C, Sonmete MH. Evaluation of global solar radiation models for Konya, Turkey. Energy Conversion and Management 2006;47(18-19):3149-73.

[9] Bakirci K. Correlations for estimation of daily global solar radiation with hours of bright sunshine in Turkey. Energy 2009;34 (4):485-501.

[10] Cybenko G. Approximation by superposition of a sigmoidal function. Mathematics of Control Signal and Systems 1989;2:303-14.

11] Reddy KS. Solar resource estimation using artificial neural networks and comparison with other correlation models. Energy Conversion and Management 2003;44 (15):251930.

[12] So"zen A. Use of artificial neural networks for mapping of solar potential in Turkey. Applied Energy 2004;77 (3):27386.

[13] Zarzalejo LF, Ramirez L, Polo J. Artificial intelligence techniques applied to hourly global irradiance estimation from satellite-derived cloud index. Energy 2005;30(9):1685-97.

[14] Mubiru J, Banda EJKB. Estimation of monthly average daily global solar irradiation using artificial neural networks. Solar Energy 2008;82(2):1-7.

[15] Rehmana S, Mohandes M. Artificial neural network estimation of global solar radiation using air temperature and relative humidity. Energy Policy 2008;36(2):571-6.

[16] Mohandes M, Balghonaim A, Kassas M, Rehman S, Halawani TO. Use of radial basis functions for estimating monthly mean daily solar-radiation. Solar Energy 2000; 68: $161-8$

[17] M.A. Behrang, E. Assareh, A. Ghanbarzadeh, A.R. Noghrehabadi. The potential of different artificial neural network (ANN) techniques in daily global solar radiation 
modeling based on meteorological data. Solar Energy 2010; 84: $1468-1480$.

[18] Haykin S. Neural networks: a comprehensive foundation. New York: Macmillan College Publishing Co; 1993.
[19] Kalogirou SA. Application of artificial neural networks in energy systems: a review. Energy Conversion Manage 1999;40:1073-87.

[20] Mani A. Handbook of solar radiation data for India. New Delhi: Allied Publishers Pvt. Ltd; 1981. 